\title{
The Effect of Pregnant Ladies Lifestyle on Pregnancy; Clinical Study in a Single Saudi Center
}

\author{
Muhammad Alsaddique and Ahmad Talal Chamsi* \\ Department of Obstetrics and Gynecology, Security Forces Hospital, Riyadh, Saudi Arabia
}

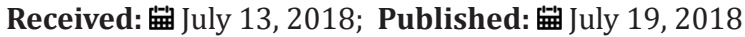

*Corresponding author: Ahmad Talal Chamsi, Department of Obstetrics and Gynecology, Security Forces Hospital, P.0. Box 3643, Saudi Arabia

\begin{abstract}
Background: Complications in pregnancy are common and threatened miscarriage is occurring in approximately $20 \%$ of all pregnancies. The present study was conducted to determine various lifestyle factors leading to threatened abortion.

Materials \& Methods: This study was conducted in the department of Gynecology and Obstectrics which included 118 women. General information such as age, marital status, gestational age (weeks), educational level; housing, number of children, prepregnancy BMI (kg/m2), regularity of menstrual cycles; presence of nausea, history of miscarriage, history of benign gynaecological conditions; smoking status, caffeine intake, mobile phone use (in hours per day), computer use (hrs/day), history of depression or schizophrenia, extent of bleeding was recorded.

Results: In our study, women with $<34$ years were 101 and $>34$ years were 17 . Women had either high school education (100) and intermediate school (18), number of children were 0 in 98 women, 1 in 14 women and 2 in 6 women. The difference was significant $(\mathrm{P}<0.05)$. Patients with $\mathrm{BMI}<25$ were 84 in number whereas with $>25$ were 34 . Women with regular menstrual cycles were 102 whereas 16 had irregular cycle. The difference was significant $(\mathrm{P}<0.01)$. 78 had nausea while 40 had not. 18 gave positive history of previous miscarriage while 100 did not. 102 patients gave positive history of termination of pregnancy and 108 had gynecological diseases, 112 had given history of smoking in pregnancy, 30 had 1 or more household having history of smoking, 82 had positive history of caffeine intake, 78 had history of mobile use more than 4 hours, 58 had history of computer use more than 4 hours, 18 had history of depression, 44 had high stress score, 96 gave history of spotting bleeding during pregnancy, 8 had threatened abortion. The difference was significant $(\mathrm{P}<0.05)$.
\end{abstract}

Conclusion: Lifestyle plays an important role the pregnancy. There is alteration in hormone level in pregnancy leading to miscarriage. Careful following of routine lifestyle prevent further complications in pregnancy.

Keywords: Miscarriage; Pregnancy; Threatened abortion

\section{Introduction}

Complications in pregnancy are common and threatened miscarriage is occurring in approximately $20 \%$ of all pregnancies. In first trimester, vaginal bleeding leads to $5.5 \%-42.7 \%$ risk for subsequent complete miscarriage. Threatened miscarriage, defined as vaginal bleeding before the 20th week of gestation, occurs in about $20 \%$ of pregnancies. One in three women with threatened miscarriage subsequently suffers a complete miscarriage [1]. Antepartum hemorrhage, preterm delivery, low birth weight etc. are other complications that can occur in women who experience such bleeding. Many studies have established numerous factors leading to complete miscarriage in the first trimester. They have enumerated increased maternal age, high pre-pregnancy body mass index (BMI) and low serum progesterone levels as various factors.
Apart from these, lifestyle factors also play important role such as exercise, stress, cigarette smoke and caffeine intake [2]. Factors as noted in clinical and ultrasonographic evaluation are maternal age, extent of vaginal bleeding, abdominal pain, gestational age at onset of bleeding, uterine size and fetal cardiac activity. Electromagnetic field (EMF) exposure associated with appliances like microwave ovens, computer use and mobile phone devices, has been linked in epidemiological studies to both leukemia risk and early pregnancy loss. Prolonged mobile-phone use, computer use and exposure to second-hand smoke are increasingly common and research is needed to establish whether these exposures are associated with risk of threatened miscarriage [3]. It has been suggested that fish oil supplementation in pregnant women may protect 
against threatened miscarriage. A study conducted by Rossi et al. have shown that a reduction in the spontaneous miscarriage rate with DHA use in women with antiphospholipid-syndrome with a history of recurrent miscarriages but the benefit of DHA in sporadic miscarriage is unknown. There should be teaching regarding lifestyle factors which enhances the risk of miscarriage and hence the chances of miscarriage can be diminished [4]. The present study was conducted to determine various lifestyle factors leading to threatened abortion.

\section{Materials and Methods}

\section{Ethical Approval}

The study was approved by the Institutional Research Committee at Security Forces Hospital

Design and Setting.

\section{Settings}

A retrospective observational cohort study was conducted at Department of Obstetrics and Gynecology, Security Forces Hospital, Riyadh, Saudi Arabia.

\section{Subjects}

The Study included 118 women. General information such as age, marital status, ethnicity, gestational age (weeks), educational level; housing, number of children, pre-pregnancy BMI (kg/m2), regularity of menstrual cycles; presence of nausea, history of

Table 1: Demographic data of patients.

\begin{tabular}{|c|c|c|}
\hline Item & Number & P Value \\
\hline \multicolumn{3}{|c|}{ Age } \\
\hline$<34$ Years & 101 & \multirow{2}{*}{0.02} \\
\hline$>34$ Years & 17 & \\
\hline \multicolumn{3}{|c|}{ Educations } \\
\hline High School and higher & 100 & \multirow{2}{*}{0.01} \\
\hline Intermediate School & 18 & \\
\hline \multicolumn{3}{|c|}{ Housing } \\
\hline Private & 6 & \multirow{2}{*}{0.01} \\
\hline Rental & 112 & \\
\hline \multicolumn{3}{|c|}{ Number of Children } \\
\hline 0 & 98 & \multirow{3}{*}{0.02} \\
\hline 1 & 14 & \\
\hline$>2$ & 6 & \\
\hline \multicolumn{3}{|c|}{ BMI } \\
\hline$<25$ & 84 & \multirow{2}{*}{0.1} \\
\hline$>25$ & 34 & \\
\hline \multicolumn{3}{|c|}{ Regular Menstrual Cycle } \\
\hline Yes & 102 & \multirow{2}{*}{0.01} \\
\hline No & 16 & \\
\hline
\end{tabular}

miscarriage, history of benign gynaecological conditions; smoking status, caffeine intake, mobile phone use (in hours per day), computer use (hrs/day), history of depression or schizophrenia, extent of bleeding was recorded.

\section{Statistical Analysis}

Data were collected and entered on Microsoft Excel. Data Analysis was carried out using Microsoft Excel 2017.

\section{Result}

Table 1 shows that women with $<34$ years were 101 and $>34$ years were 17. Women had either high school education (100) and intermediate school (18), number of children were 0 in 98 women, 1 in 14 women and 2 in 6 women. The difference was significant $(\mathrm{P}<0.05)$. Patients with BMI $<23$ were 84 in number whereas with $>23$ were 34. Women with regular menstrual cycles were 102 whereas 16 had irregular cycle. The difference was significant $(\mathrm{P}<0.01) .78$ had nausea while 40 had not. 18 gave positive history of previous miscarriage while 100 did not. Table 2 shows that 102 patients gave positive history of termination of pregnancy and 108 had gynecological diseases, 112 had given history of smoking in pregnancy, 30 had 1 or more household having history of smoking, 82 had positive history of caffeine intake, 78 had history of mobile use more than 4 hours, 58 had history of computer use more than 4 hours, 18 had history of depression, 44 had high stress score, 96 gave history of spotting bleeding during pregnancy, 8 had threatened abortion. The difference was significant $(\mathrm{P}<0.05)$. 


\begin{tabular}{|c|c|c|}
\hline \multicolumn{2}{|c|}{ History of Miscarriage } & \multirow{2}{*}{0.01} \\
\hline Yes & 18 & 100 \\
\hline No & & 0.01 \\
\hline
\end{tabular}

Table 2: Patients' Data.

\begin{tabular}{|c|c|c|}
\hline Item & Number & P Value \\
\hline \multicolumn{3}{|c|}{ History of Termination of Pregnancy } \\
\hline Yes & 16 & \multirow{2}{*}{0.02} \\
\hline No & 102 & \\
\hline \multicolumn{3}{|c|}{ Gynecological Disorders } \\
\hline Yes & 10 & \multirow{2}{*}{0.02} \\
\hline No & 108 & \\
\hline \multicolumn{3}{|c|}{ Smoking in Pregnancy } \\
\hline Yes & 6 & \multirow{2}{*}{0.01} \\
\hline No & 112 & \\
\hline \multicolumn{3}{|c|}{ Caffeine Intake } \\
\hline Yes & 82 & \multirow{2}{*}{0.01} \\
\hline No & 36 & \\
\hline \multicolumn{3}{|c|}{ Computer Usage } \\
\hline $0-1$ & 22 & \multirow{3}{*}{0.01} \\
\hline $1-4$ & 38 & \\
\hline$>4$ & 58 & \\
\hline \multicolumn{3}{|c|}{ Mobile Usage } \\
\hline $0-1$ & 16 & \multirow{3}{*}{0.01} \\
\hline $1-4$ & 24 & \\
\hline$>4$ & 78 & \\
\hline \multicolumn{3}{|c|}{ History of Depression } \\
\hline Yes & 18 & \multirow{2}{*}{0.01} \\
\hline No & 100 & \\
\hline
\end{tabular}

\section{Discussion}

Life style play important role in the pregnancy. It has severe deleterious effects on the fetus. Irregular lifestyle can result into threatened abortion. The present study was conducted to determine various lifestyle factors leading to threatened abortion. We found that women $>34$ years of age were 17 . Advanced maternal age was a significant risk factor for miscarriage in the group of women in the present study. Women aged $\geq 34$ years at presentation were more likely to have a complete miscarriage than women who were younger. This is consistent with previous studies, which showed that the risk of miscarriage is generally higher in pregnant women of greater age $[5,6]$. Patients with BMI $<25$ were 84 in number whereas with $>25$ were 34 . Women with regular menstrual cycles were 102 whereas 16 had irregular cycle. This agrees with the results of Saraswat et al. [7] 18 gave positive history of previous miscarriage which shows that previous miscarriage can lead to miscarriage in future too. This is similar to results of Lashen et al. [8] 16 patients gave positive history of termination of pregnancy and
10 had gynecological diseases, 112 had given history of smoking in pregnancy, 30 had 1 or more household having history of smoking, and 82 had positive history of caffeine intake. This shows that smoking has harmful effect on fetus. This is in agreement with Maconochie et al. [9] Authors have suggested the role of alteration in progesterone hormone in pregnancy and pregnant women are at high risk of threatened abortion [10]. We found that 78 had history of mobile use more than 4 hours, 58 had history of computer use more than 4 hours. This shows that excessive mobile and computer use can be precipitating factor leading to miscarriage. Depression is another important factor leading to miscarriage. In our study, 18 had history of positive history of depression. 44 had high stress score. This agrees with the results of Ong CY et al. [11].

\section{Conclusion}

Lifestyle plays an important role the pregnancy. There is alteration in hormone level in pregnancy leading to miscarriage. Careful following of routine lifestyle prevent further complications in pregnancy. 


\section{References}

1. Gracia CR, Sammel MD, Chittams J, Hummel AC, Shaunik A, et al. (2005) Risk factors for spontaneous abortion in early symptomatic firsttrimester pregnancies. Obstet Gynecol 106(5): 993-999.

2. Furneaux EC, Langley-Evans AJ, Langley-Evans SC (2001) Nausea and vomiting of pregnancy: endocrine basis and contribution to pregnancy outcome. Obstet Gynecol Surv 56(12): 775-782.

3. Yaron Y, Ochshorn Y, Heifetz S, Lehavi O, Sapir Y, et al. (2002) First trimester maternal serum free human chorionic gonadotropin as a predictor of adverse pregnancy outcome. Fetal Diagn Ther 17(6): 352356.

4. Cleary-Goldman J, Malone FD, Vidaver J, Ball RH, Nyberg DA, et al. (2005) Impact of maternal age on obstetric outcome. Obstet Gynecol 105(5): 983-990.

5. De la Rochebrochard E, Thonneau P (2002) Paternal age and maternal age are risk factors for miscarriage; results of a multicentre European study. Hum Reprod 17(6): 1649-1656.
6. De La Rochebrochard E, Thonneau P (2003) Paternal age >or=40 years: an important risk factor for infertility. Am J Obstet Gynecol 189(4): 901905.

7. Saraswat L, Bhattacharya S, Maheshwari A, Bhattacharya S (2010) Maternal and perinatal outcome in women with threatened miscarriage in the first trimester: a systematic review. BJOG 117(3): 245-257.

8. Lashen H, Fear K, Sturdee DW (2004) Obesity is associated with increased risk of first trimester and recurrent miscarriage: matched case-control study. Hum Reprod 19(7): 1644-1646.

9. Maconochie N, Doyle P, Prior S, Simmons R (2007) Risk factors for first trimester miscarriage- results from a UKpopulation-based case-control study. BJOG 114(2): 170-186.

10. Basama FM, Crosfill F (2004) The outcome of pregnancies in 182 women with threatened miscarriage. Arch Gynecol Obstet 270(2): 86-90.

11. Ong CY, Liao AW, Spencer K, Munim S, Nicolaides KH (2000) First trimester maternal serum free beta human chorionic gonadotrophin and pregnancy associated plasma protein A as predictors of pregnancy complications. BJOG 107(10): 1265-1270.

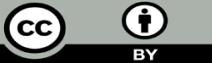

This work is licensed under Creative Commons Attribution 4.0 License

Submission Link:

\section{Submit Article}

